\title{
Several ways one goal—methanogenesis from unconventional substrates
}

\author{
Julia M. Kurth ${ }^{1}$ (D) Huub J. M. Op den Camp ${ }^{1}$ (i) $\cdot$ Cornelia U. Welte ${ }^{1,2}$ (i) \\ Received: 8 April 2020 /Revised: 27 May 2020 / Accepted: 4 June 2020 / Published online: 15 June 2020 \\ (C) The Author(s) 2020
}

\begin{abstract}
Methane is the second most important greenhouse gas on earth. It is produced by methanogenic archaea, which play an important role in the global carbon cycle. Three main methanogenesis pathways are known: in the hydrogenotrophic pathway $\mathrm{H}_{2}$ and carbon dioxide are used for methane production, whereas in the methylotrophic pathway small methylated carbon compounds like methanol and methylated amines are used. In the aceticlastic pathway, acetate is disproportionated to methane and carbon dioxide. However, next to these conventional substrates, further methanogenic substrates and pathways have been discovered. Several phylogenetically distinct methanogenic lineages (Methanosphaera, Methanimicrococcus, Methanomassiliicoccus, Methanonatronarchaeum) have evolved hydrogen-dependent methylotrophic methanogenesis without the ability to perform either hydrogenotrophic or methylotrophic methanogenesis. Genome analysis of the deep branching Methanonatronarchaeum revealed an interesting membrane-bound hydrogenase complex affiliated with the hardly described class $4 \mathrm{~g}$ of multisubunit hydrogenases possibly providing reducing equivalents for anabolism. Furthermore, methylated sulfur compounds such as methanethiol, dimethyl sulfide, and methylmercaptopropionate were described to be converted into adapted methylotrophic methanogenesis pathways of Methanosarcinales strains. Moreover, recently it has been shown that the methanogen Methermicoccus shengliensis can use methoxylated aromatic compounds in methanogenesis. Also, tertiary amines like choline ( $N, N, N$-trimethylethanolamine) or betaine ( $N, N, N$-trimethylglycine) have been described as substrates for methane production in Methanococcoides and Methanolobus strains. This review article will provide in-depth information on genome-guided metabolic reconstructions, physiology, and biochemistry of these unusual methanogenesis pathways.
\end{abstract}

\section{Key points}

- Newly discovered methanogenic substrates and pathways are reviewed for the first time.

- The review provides an in-depth analysis of unusual methanogenesis pathways.

- The hydrogenase complex of the deep branching Methanonatronarchaeum is analyzed.

Keywords Methane production $\cdot$ Extended substrate range $\cdot$ Novel pathways $\cdot$ Archaea

Huub J. M. Op den Camp

h.opdencamp@science.ru.nl

Cornelia U. Welte

c.welte@science.ru.nl

1 Department of Microbiology, Institute for Water and Wetland Research, Radboud University, Heyendaalseweg 135, 6525 AJ Nijmegen, The Netherlands

2 Soehngen Institute of Anaerobic Microbiology, Radboud University, Heyendaalseweg 135, 6525 AJ Nijmegen, The Netherlands

\section{Introduction}

Methane is an important greenhouse gas with an atmospheric budget of about $600 \mathrm{Tg}$ per year (Conrad 2009). About 70\% of the emitted methane is produced by methanogenic archaea (Conrad 2009) underlining the importance of methanogenesis for the global carbon cycle. In addition to their role in the environment and the global carbon cycle, methanogens can be used for several applications. They gain increasing importance for energy supply and the production of high-value compounds in the chemical industry (Enzmann et al. 2018). Besides their pivotal role in biogas plants, methanogens are also used in microbial electrosynthesis using $\mathrm{CO}_{2}$ and 
electrical power to generate methane. Three main methanogenesis pathways (hydrogenotrophic, aceticlastic, and methylotrophic) have been described that share the core pathway of methanogenesis yet also differ in many aspects of their biochemistry and physiology.
The largest phylogenetic diversity is found within the hydrogenotrophic methanogens. They utilize hydrogen as an electron donor for the reduction of carbon dioxide to methane (Fig. 1A). Two main hydrogenases are used for the oxidation of dihydrogen: the soluble $\mathrm{F}_{420}$-reducing hydrogenase Frh
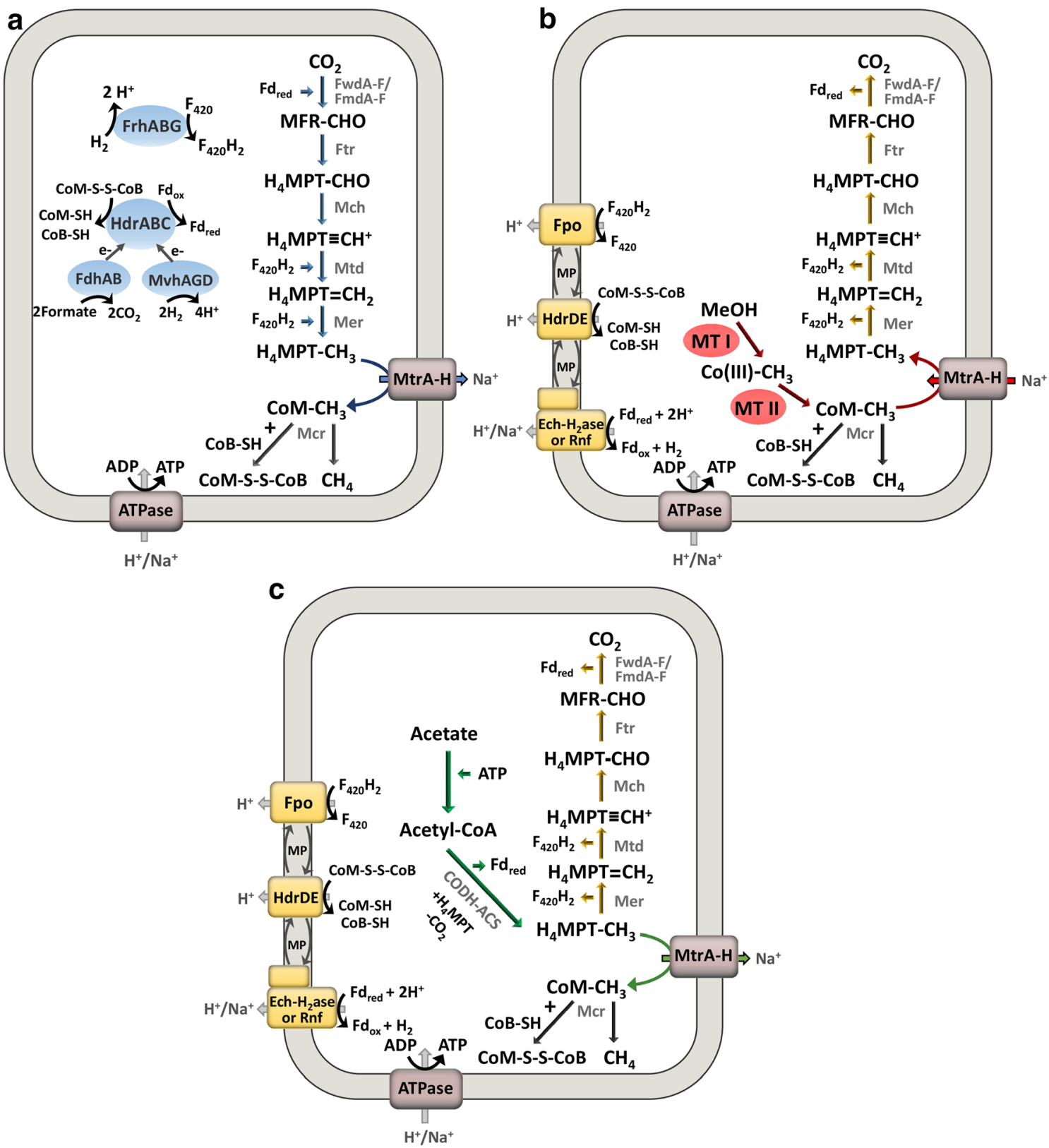

Fig. 1 Hydrogenotrophic (a), methylotrophic (b) and aceticlastic (c) methanogenesis pathways. The ferredoxin electron carrier is a twoelectron carrier. Some methanogens use a $\mathrm{H}_{4} \mathrm{MPT}$ derivative called tetrahydrosarcinopterin $\left(\mathrm{H}_{4} \mathrm{SPT}\right)$. The $\mathrm{Na}^{+} / \mathrm{H}^{+}$translocation stoichiometry is not represented in the figure. FwdA-F/FmdA-F: formylmethanofuran dehydrogenase, Ftr: formylmethanofurantetrahydromethanopterin formyl-transferase, Mch: methenyltetrahydromethanopterin cyclohydrolase, Mtd: methylenetetrahydromethanopterin dehydrogenase, Mer: 5,10methylenetetrahydromethanopterin reductase, MtrA-H: tetrahydromethanopterin S-methyl-transferase, McrABCDG methyl- coenzyme $\mathrm{M}$ reductase, FrhABG: coenzyme $\mathrm{F}_{420}$-reducing hydrogenase, HdrABC: soluble heterodisulfide reductase, MvhAGD: $\mathrm{F}_{420}$-non-reducing hydrogenase, FdhAB: formate dehydrogenase, FpoA-O: $\mathrm{F}_{420} \mathrm{H}_{2}$ dehydrogenase, HdrDE: membrane-bound heterodisulfide reductase, Ech$\mathrm{H}_{2}$ ase: energy-converting hydrogenase, $\mathrm{Rnf}: \mathrm{Na}^{+}$-translocating ferredoxin:NAD ${ }^{+}$oxidoreductase complex, ATPase: ATP synthase, CODH-ACS: Acetyl-CoA decarbonylase/synthase, MTI and MTII: methyltransferase, CoB: coenzyme B, CoM: coenzyme M, $\mathrm{H}_{4} \mathrm{MPT}$ : tetrahydromethanopterin, MFR: methanofuran, Fd: ferredoxin, $\mathrm{F}_{420} \mathrm{H}_{2}$ : reduced coenzyme $\mathrm{F}_{420}$, MP: methanophenazine, $\mathrm{CO}(\mathrm{III})$ : cobalamin binding protein 
reduces the methanogenic cofactor $\mathrm{F}_{420}$ to $\mathrm{F}_{420} \mathrm{H}_{2}$ which is subsequently re-oxidized during the reduction of carbon dioxide to methane. The soluble Mvh hydrogenase forms a complex with a heterodisulfide reductase (HdrABC) and couples the oxidation of dihydrogen to the reduction of ferredoxin and the heterodisulfide CoM-S-S-CoB in a process called flavinbased electron bifurcation (Kaster et al. 2011). The reduced ferredoxin is required for the first step of methanogenesis, the reduction of carbon dioxide to a cofactor-bound formyl group. The CoM functions as a methyl carrier and forms the heterodisulfide together with $\mathrm{CoB}$ in the last step of methanogenesis. To replenish the cell with reduced ferredoxin which is also required for the biosynthesis of cell components from $\mathrm{CO}_{2}$ some methanogens use energy-converting hydrogenases such as Eha catalyzing the sodium motive force-driven reduction of ferredoxin with $\mathrm{H}_{2}$ (Thauer 2012). Energy conservation during hydrogenotrophic methanogenesis happens exclusively during a methyl transfer reaction that is part of the core pathway of methanogenesis. The responsible membrane-bound methyltransferase Mtr translocates sodium ions across the membrane leading to the buildup of a sodium motive force that is subsequently used by an ATP synthase.

Aceticlastic methanogenesis (Fig. 1C) is performed by Methanosarcinaceae and Methanotrichaceae (formerly named Methanosaetaceae). Acetate enters the cell via an acetate transporter (Welte et al. 2014) and is subsequently activated to acetyl-CoA, either by the concerted action of acetate kinase and transacetylase (in Methanosarcinaceae) or by the activity of acetyl-CoA synthetase (in Methanotrichaceae, Berger et al. 2012). After acetate activation to acetyl-CoA, the molecule is dismutated through the enzyme acetyl-CoA decarbonylase/synthase: the carbonyl group is oxidized to carbon dioxide whereas the methyl group is funneled into the central methanogenic pathway in order to be reduced to methane. Energy conservation happens at the membrane-bound methyltransferase Mtr as well as in a membrane-bound electron transport chain that utilizes reduced ferredoxin and the heterodisulfide which both are produced during methanogenesis (Welte and Deppenmeier 2014). During aceticlastic methanogenesis, more $\mathrm{Na}^{+} / \mathrm{H}^{+}$ions translocate during a single round of methanogenesis compared with hydrogenotrophic methanogenesis, yet the former pathway of methanogenesis also requires an initial ATP investment during the activation of acetate to acetyl-CoA.

Methylotrophic methanogenesis (Fig. 1B) is performed by members of the Methanosarcinales. They possess substratespecific methyltransferase systems for the utilization of methanol and methylated amines. These enzyme systems consist of three components: a substrate-specific methyltransferase that transfers the methyl group to a corrinoid protein. Subsequently, a second methyltransferase funnels the methyl group into the methanogenic pathway at the stage of methyl-CoM. Three quarters of the methyl groups are reduced to methane whereas one quarter is oxidized to carbon dioxide, in order to generate reducing equivalents as electron donors for a membrane-bound electron transport chain that uses the heterodisulfide as an electron acceptor. Energy conservation only happens during membrane-bound electron transport, as the membrane-bound methyltransferase operates in the reverse reaction, thereby dissipating the proton/ sodium motive force.

In addition, a broad range of substrates can be converted by syntrophic interaction of methanogens and bacteria that closely cooperate in methanogenic degradation. The methanogenic degradation of fatty acids, alcohols, most aromatic compounds and amino acids, and others is performed in syntrophy between fermenting bacteria and methanogenic archaea (Worm et al. 2010).

Besides the canonical methanogenesis pathways described above and syntrophic interactions of methanogens and bacteria, methanogens are capable of methane generation from additional substrates, which is much less widely known and also less appreciated in environmental studies. In this review article, we will describe the current knowledge of methanogenesis pathways that go beyond the three pathways outlined above, and identify current knowledge gaps.

\section{Hydrogenotrophic methanogenesis with additional electron donors}

\section{Formate}

Many hydrogenotrophic methanogens can use formate instead of $\mathrm{H}_{2}$ to make methane from $\mathrm{CO}_{2}$ (Fig. 2). For the conversion of formate, these methanogens use the enzyme formate dehydrogenase. The activity of this enzyme, consisting of the two subunits FdhA and FdhB, leads to the production of reduced coenzyme $\mathrm{F}_{420}$ (Jones and Stadtman 1979; Schauer and Ferry 1982, 1986). Moreover, it has been shown that an electron bifurcating enzyme complex can couple formate oxidation to heterodisulfide reduction (Costa et al. 2010).

\section{Carbon monoxide}

Some methanogens like Methanosarcina acetivorans can use carbon monoxide as a growth substrate, producing methane via a pathway that involves hydrogen as an intermediate (Rother and Metcalf 2004). Methanosarcina acetivorans $\mathrm{C} 2 \mathrm{~A}$ was shown to rather produce acetate and formate from $\mathrm{CO}$ than methane. Resting cell experiments demonstrated that methane production decreased linearly with increasing $\mathrm{CO}$ partial pressures, consistent with inhibition of methanogenesis by $\mathrm{CO}$. Phosphotransacetylase and acetate kinase were required for growth on acetate and $\mathrm{CO}$ as growth substrates, i.e., aceticlastic methanogenesis and carboxydotrophic acetogenesis. Moreover, it has been found that a 


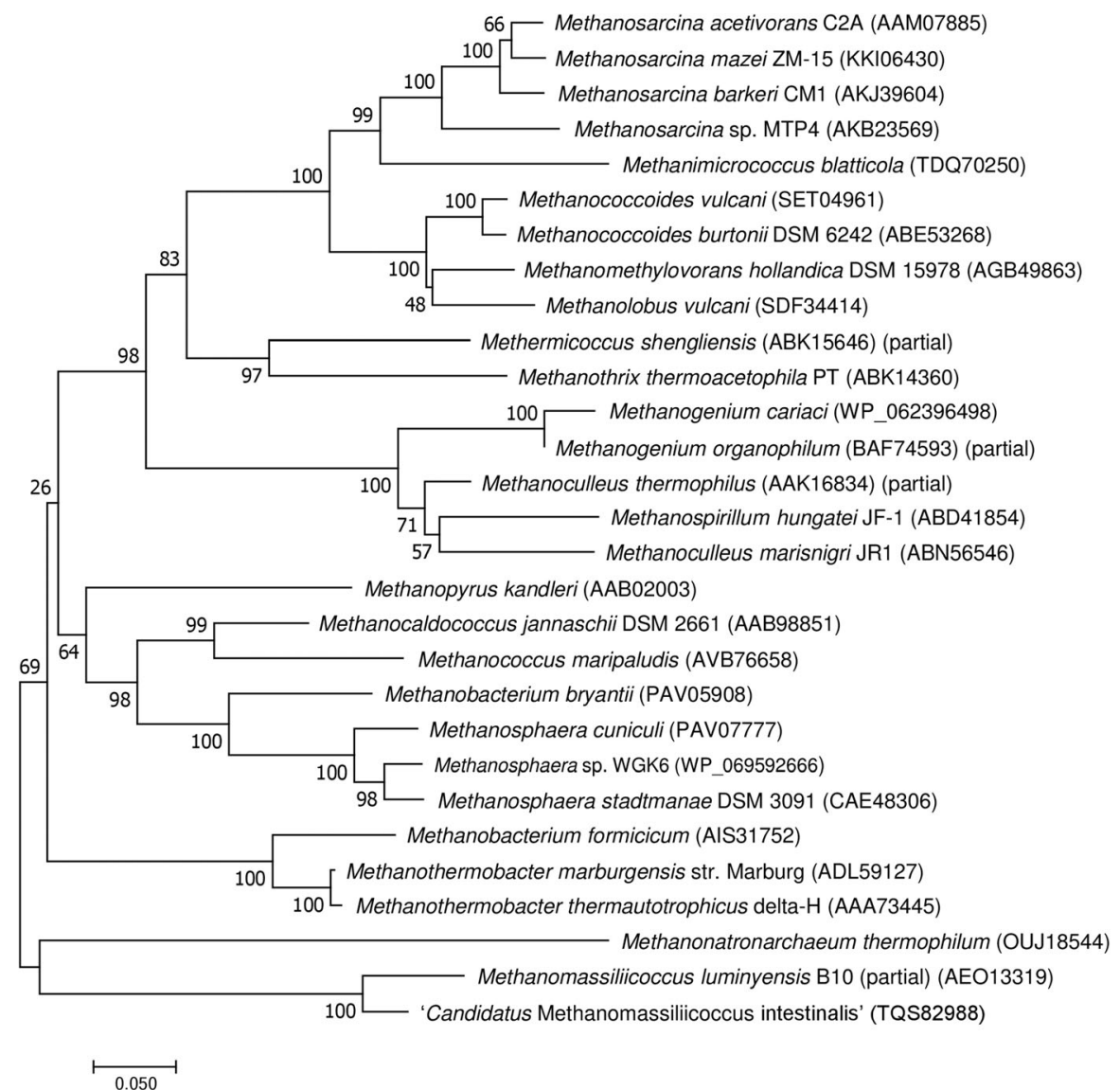

$\mathrm{CO}$, Acetate, $\mathrm{MeOH}, \mathrm{MA}, \mathrm{MS}$

$\mathrm{H}_{2} / \mathrm{CO}_{2}$, Acetate, MeOH, MA, Fell

$\mathrm{H}_{2} / \mathrm{CO}_{2}$, Acetate, $\mathrm{MeOH}, \mathrm{MA}$, MS, Fell

Acetate, MeOH, MA, MS

$\mathrm{H}_{2} / \mathrm{MeOH}, \mathrm{H}_{2} / \mathrm{MA}$

$\mathrm{MeOH}, \mathrm{MA}, \mathrm{TA}, \mathrm{QA}$

$\mathrm{MeOH}, \mathrm{MA}$

MeOH, MA, MS

$\mathrm{MeOH}, \mathrm{MA}, \mathrm{QA}$

$\mathrm{MeOH}, \mathrm{MA}$, Methoxy compounds

Acetate

$\mathrm{H}_{2} / \mathrm{CO}_{2}$, Formate/ $/ \mathrm{CO}_{2}$

$\mathrm{H}_{2} / \mathrm{CO}_{2}$, Formate $/ \mathrm{CO}_{2}$, Sec.alcohols $/ \mathrm{CO}_{2}$

$\mathrm{H}_{2} / \mathrm{CO}_{2}$, Formate $/ \mathrm{CO}_{2}$, Sec.alcohols $/ \mathrm{CO}_{2}$

$\mathrm{H}_{2} / \mathrm{CO}_{2}$, Formate $/ \mathrm{CO}_{2}$, Sec. alcohols $/ \mathrm{CO}_{2}$

$\mathrm{H}_{2} / \mathrm{CO}_{2}$, Formate $/ \mathrm{CO}_{2}$, Sec. alcohols $/ \mathrm{CO}_{2}$

$\mathrm{H}_{2} / \mathrm{CO}_{2}$

$\mathrm{H}_{2} / \mathrm{CO}_{2}$

$\mathrm{H}_{2} / \mathrm{CO}_{2}$, Formate $/ \mathrm{CO}_{2}$

$\mathrm{H}_{2} / \mathrm{CO}_{2}$, Formate $/ \mathrm{CO}_{2}$, Sec. alcohols $/ \mathrm{CO}_{2}$

$\mathrm{H}_{2} / \mathrm{MeOH}$

$\mathrm{EtOH}, \mathrm{MeOH}, \mathrm{H}_{2} / \mathrm{MeOH}$

$\mathrm{H}_{2} / \mathrm{MeOH}$

$\mathrm{H}_{2} / \mathrm{CO}_{2}$, Formate $/ \mathrm{CO}_{2}$, Sec. alcohols $/ \mathrm{CO}_{2}$

$\mathrm{H}_{2} / \mathrm{CO}_{2}$, (Formate?)

$\mathrm{H}_{2} / \mathrm{CO}_{2}$, Formate $/ \mathrm{CO}_{2}$

$\mathrm{MeOH}+\mathrm{H}_{2} /$ Formate

$\mathrm{H}_{2} / \mathrm{MeOH}, \mathrm{H}_{2} / \mathrm{MA}$

$\mathrm{H}_{2} / \mathrm{MeOH}$

$\stackrel{\vdash}{\longmapsto .050}$

Fig. 2 Evolutionary relationships of methyl-coenzyme M reductase (subunit A) of different methanogens. The evolutionary history was inferred using the Neighbor-Joining method. The optimal tree with the sum of branch length $=3.29201331$ is shown. The percentage of replicate trees in which the associated taxa clustered together in the bootstrap test (500 replicates) are shown next to the branches. The tree is drawn to scale, with branch lengths in the same units as those of the evolutionary distances used to infer the phylogenetic tree. The evolutionary distances

monofunctional carbon monoxide dehydrogenase (CODH) system contributes to, but is not required for, carboxydotrophic growth of $M$. acetivorans and that the bifunctional acetyl-CoA decarbonylase/synthase system is synthesized at elevated levels in response to $\mathrm{CO}$ (Rother et al. 2007). Further, CmtA (MA4384) is a soluble $\mathrm{CH}_{3}$ tetrahydrosarcinapterin:HS-CoM methyltransferase postulated to supplement the membrane-bound $\mathrm{CH}_{3}$ tetrahydrosarcinapterin:HS-CoM methyltransferase during CO-dependent growth of $M$. acetivorans (Vepachedu and Ferry 2012). Tetrahydrosarcinopterin is an analog to the $\mathrm{C}_{1^{-}}$carrier tetrahydromethanopterin $\left(\mathrm{H}_{4} \mathrm{MPT}\right)$ which is most commonly used for $\mathrm{C}_{1}$-group transfer in methanogens. The soluble $\mathrm{CmtA}$ and homologs potentially provide a mechanism for bypassing MtrA-H, allowing growth at otherwise prohibitively low $\mathrm{CO}$ concentrations and equipping the cell to accommodate fluctuations in the $\mathrm{CO}$ concentrations that are encountered in the environment, thereby maximizing the thermodynamic efficiency for optimal ATP synthesis and growth by were computed using the Dayhoff matrix-based method and are in the units of the number of amino acid substitutions per site. The analysis involved 29 amino acid sequences. All ambiguous positions were removed for each sequence pair. There were a total of 583 positions in the final dataset. Evolutionary analyses were conducted in MEGA7 (Kumar et al. 2016). MA: methylamines, MS: methylated sulfur compounds, TA: tertiary amines, QA: quaternary amines

partitioning methyl transfer through CmtA and MtrA-H (Vepachedu and Ferry 2012).

\section{Ethanol}

Some Methanobrevibacter sp. (Methanobacteriales) are capable of using ethanol as an electron donor for $\mathrm{CO}_{2}$ reduction to methane, yet not in the absence of hydrogen (Leahy et al. 2013; Poehlein et al. 2018). They possess the walC and walD alcohol and aldehyde dehydrogenase genes which enable them to convert ethanol to acetate. Also, a member of the Methanomicrobiales, Methanofollis ethanolicus, is able to grow with $\mathrm{CO}_{2}$ and ethanol as a electron donor (Imachi et al. 2009). The M. ethanolicus genome (Narihiro et al. 2016) encodes three sets of alcohol and aldehyde dehydrogenases (iron-dependent alcohol dehydrogenases: MEFOE RS00535, MEFOE RS00570, MEFOE RS02725; aldehyde dehydrogenases: MEFOE RS06760, MEFOE_RS07165, MEFOE_RS03840). Several 
Methanosarcina and Methanoculleus genomes encode homo$\log$ s to the $M$. ethanolicus alcohol and aldehyde deydrogenases indicating that the trait of using ethanol as electron donor might be more widespread; however, these genome-based predictions need to be experimentally validated. A Methanosphaera strain isolated from the kangaroo foregut was capable of reducing methanol with ethanol as a electron donor (Hoedt et al. 2016); as this methanogen is not capable of hydrogenotrophic methanogenesis, it will be discussed under "hydrogen-dependent methylotrophic methanogenesis."

\section{Propanol/2-butanol}

Three methanogen strains, two mesophilic, and one thermophilic strain, were isolated with 2-propanol as the hydrogen donor for methanogenesis from $\mathrm{CO}_{2}$ (Widdel 1986; Widdel et al. 1988). The strains were designated Methanogenium thermophilum, Methanogenium organophilum, and Methanospirillum hungatei. One mole of $\mathrm{CH}_{4}$ was formed by $\mathrm{CO}_{2}$ reduction, with four moles of 2-propanol being converted to acetone. In addition to 2-propanol, the isolates used 2-butanol, $\mathrm{H}_{2}$, or formate and one strain even ethanol and 1-propanol (Fig. 3; Widdel 1986); however, growth was poor compared to the use of $\mathrm{H}_{2}$ and $\mathrm{CO}_{2}$ as substrates (Zellner and Winter 1987). Each secondary alcohol was oxidized to its ketone. Other methanogens like Methanobacterium formicicum, Methanogenium marisnigri, Methanospirillum hungatei strain GP1, Methanobacterium bryantii, Methanomicrobium paynteri, and Methanocorpusculum parvum were also able to grow on secondary alcohols (Zellner and Winter 1987; Widdel et al. 1988). The genome of Methanospirillum hungatei JF-1 (Gunsalus et al. 2016) contains one gene for an iron-dependent alcohol dehydrogenase (MHUN_RS00885) that is also present in other Methanospirillum genomes and furthermore similar to alcohol dehydrogenases found in sulfate-reducing bacteria. The genome of Methanogenium cariaci JCM10550 also encodes for an iron-containing alcohol dehydrogenase (JCM10550_RS03520) which is about 50\% identical to the Methanospirillum protein. Homologs of these alcohol dehydrogenases are found in other members of the

\section{Additional/alternative substrates for hydrogenotrophic methanogenesis}

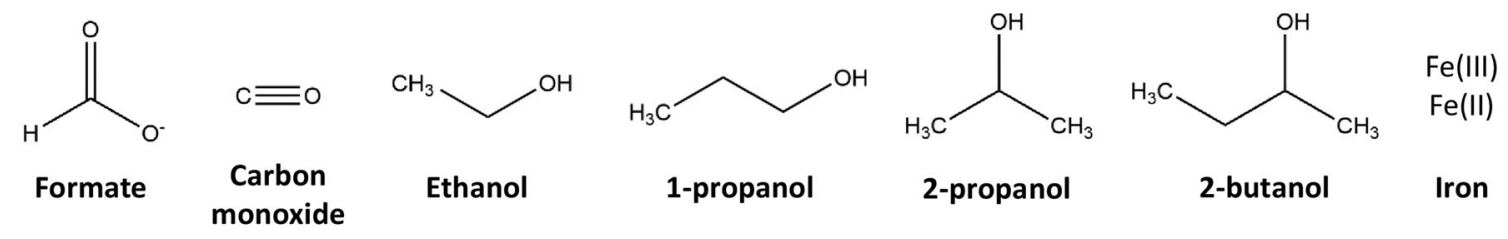

\section{Hydrogen-dependent methylotrophic methanogenesis}<smiles>CCCCCCC(C)N(C)C</smiles>

\section{Additional/alternative substrates for methylotrophic methanogenesis}

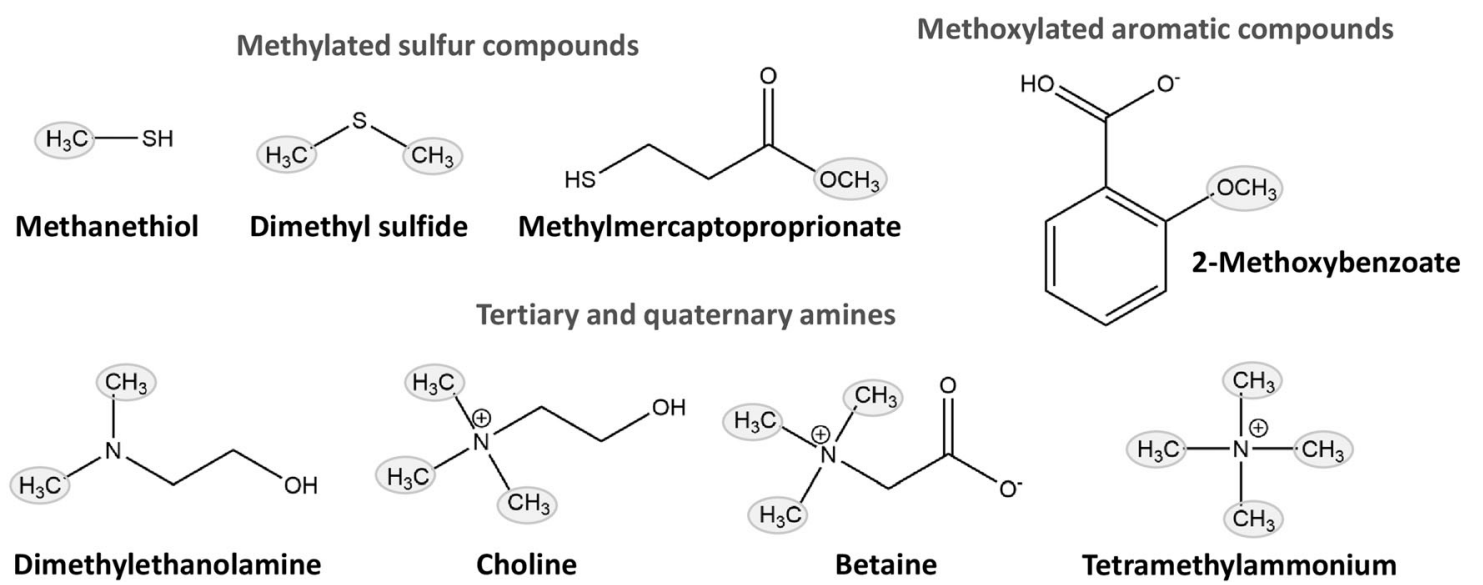

Fig. 3 Extended substrate range of methanogens. 2-Methoxybenzoate is only one example for methoxylated aromatic compounds that can be used for methanogenesis (Mayumi et al. 2016) 
Methanomicrobiales (Methanoplanus, Methanolacinia, Methanoculleus, Methanofollis). Whether this enzyme is responsible for the conversion of secondary alcohols needs to be determined experimentally.

\section{Iron}

Aceticlastic methanogenesis by Methanosarcina mazei is accelerated by magnetite and is correlated with the redox cycling of $\mathrm{Fe}$ (II) and Fe(III) in the mineral (Wang et al. 2020). The genomic analysis predicts that in addition to electron transfer components essential for aceticlastic methanogenesis, $M s$. mazei contains an outer surface multiheme $c$-type cytochrome (MHC) and a few function-unknown surface proteins that harbor monoheme motifs. It is hypothesized that the redox cycling of nanoFe $\mathrm{O}_{4}$ delivers a positive influence via the $\mathrm{MHC}$ to the membrane electron transfer chain and hence promotes aceticlastic methanogenesis.

Two species (M. barkeri and Methanococcus voltae) reduced significant amounts of Fe(III) oxide using hydrogen as the electron donor, and $0.1 \mathrm{mM}$ of anthraquinone-2,6-disulphonate (AQDS) as soluble electron shuttle in the medium greatly accelerated $\mathrm{Fe}$ (III) reduction by these organisms (Bond and Lovley 2002). Moreover, it was demonstrated that electrons were transferred to Fe(III) by hydrogen-utilizing methanogens even when growth and methanogenesis were inhibited.

\section{Hydrogen-dependent methylotrophic methanogenesis}

Next to the three common methanogenesis pathways, some methanogens use a mixed-mode of methanogenesis by combining the hydrogenotrophic and the methylotrophic pathway, which is seen as a novel mode of energy metabolism in methanogenic archaea. Such an $\mathrm{H}_{2}$-dependent methylotrophic methanogenesis pathway is used in Methanosphaera stadtmanae, belonging to the Methanobacteriales, Methanimicrococcus blatticola, belonging to the Methanosarcinales, in Methanomassiliicoccales like Methanomassilicoccus luminyensis, or in Methanonatronarchaeales like Methanonatronarchaeum thermophilum. These methanogens have in common that they lack (or do not express) the upper part of the methanogenesis pathway in which cofactor-bound methyl groups are oxidized to carbon dioxide or vice versa, explaining why they are incapable of methanogenesis from either methylated compounds or $\mathrm{H}_{2}+\mathrm{CO}_{2}$ alone. In addition, all of those organisms - except the deep branching Methanonatronarchaeum - have in common that they thrive in a gut system and therefore this type of metabolism might be an adaption to this specific environment.

Methanimicrococcus blatticola was isolated from the hindgut of a cockroach and produces methane by the reduction of methanol and methylated amines with molecular hydrogen
(Sprenger et al. 2000). It was shown that M. blatticola lacks the pathway for methyl-CoM oxidation to $\mathrm{CO}_{2}$ (Fig. 4A), explaining the requirement of hydrogen for methane production from methanol or methylated amines and the obligate heterotrophy of the organism (Sprenger et al. 2005). A further observation was that the reduction of CoM-S-S-CoB was associated with the membrane fraction of this organism hinting towards the presence of the membrane-associated heterodisulfide reductase subunit HdrD. Moreover, a hydrogen-dependent reduction of CoB-S-S-CoM could mainly be associated with the membrane fraction (Sprenger et al. 2005). Recently, the full genome sequence of M. blatticola became available, providing novel insights into the energy conservation during $\mathrm{H}_{2}$-dependent methylotrophic methanogenesis in this organism. The genome encodes a membrane-bound methanophenazine-reducing hydrogenase homologous to the cytochrome $b$ containing NiFehydrogenase (Vht hydrogenase) found in Methanosarcina (encoded by the gene cluster C7391_RS00170C7391_RS00185) as well as a cytoplasmic $\mathrm{F}_{420}$-reducing hydrogenase (C7391_RS03665-3670) (Fig. 4A, Table 1). In addition, a membrane-bound heterodisulfide reductase consisting of the subunits HdrDE was detected (C7391_RS01355, C7391_RS01360). No genes encoding for an $\mathrm{F}_{420} \mathrm{H}_{2}$ dehydrogenase (Fpo complex) or an Ech/Eha/ Ehb hydrogenase could be identified which often plays a role in regenerating $\mathrm{F}_{420}$ and oxidized/reduced ferredoxin. These results indicate that energy conservation is happening at a simple $\mathrm{H}_{2}$-dependent respiratory chain where $\mathrm{H}_{2}$ is oxidized by the methanophenazine-reducing hydrogenase, followed by electron shuttling through methanophenazine to the membrane-bound heterodisulfide reductase. Both enzyme complexes contribute to the formation of a proton gradient that can subsequently be used for ATP synthesis.

Methanosphaera stadtmanae has been isolated from the human gut and also strictly requires hydrogen for methane production from methanol (Miller and Gennis 1985). Although the organism still encodes for most of the genes required for methyl oxidation to $\mathrm{CO}_{2}$, it has lost the capability to oxidize methanol to $\mathrm{CO}_{2}$ and vice versa (Fig. 4B; van de Wijngaard et al. 1991; Fricke et al. 2006). The remaining proteins of the upper methanogenesis pathway are assumed to be used in other metabolic pathways like purine and amino acid metabolism (van de Wijngaard et al. 1991). Acetyl-CoA decarbonylase/synthase is absent in M. stadtmanae which is why it cannot synthesize acetate from inorganic precursors, explaining its requirement for acetate in the growth medium (Fricke et al. 2006). In the genome of M. stadtmanae genes for three different hydrogenases are found: the $\mathrm{F}_{420}$-reducing hydrogenase FrhADGB (Msp 1302 to Msp 1305), the cytoplasmic $\mathrm{F}_{420}$-nonreducing hydrogenase MvhDGA (Msp_0314 to Msp_0316) and the energy-conserving hydrogenases EhbABCDEFGHIJKLM-NOPQ (Msp_1457 to 

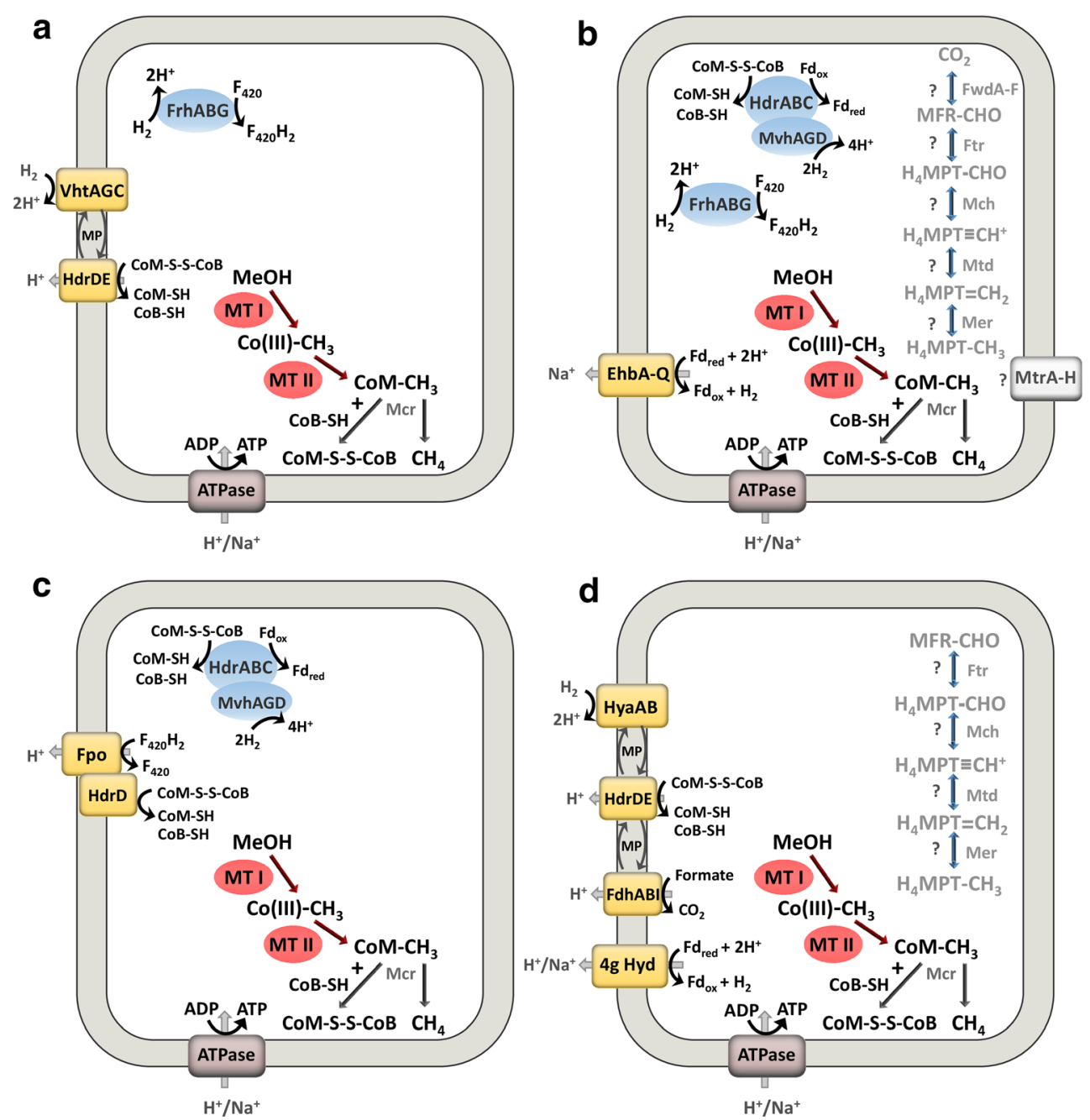

Fig. 4 Methanogenesis pathway in Methanimicrococcus blatticola (a), Methanosphaera stadtmanae (b), Methanomassiliicoccus luminyensis (c), and Methanonatronarchaeum thermophilum (d) Question marks mark proteins which are encoded in the distinctive genome, but their abundance and function in the cell are yet unclear. The ferredoxin electron carrier is a 2-electron carrier. Some methanogens use a $\mathrm{H}_{4} \mathrm{MPT}$ derivative called tetrahydrosarcinopterin $\left(\mathrm{H}_{4} \mathrm{SPT}\right)$. The $\mathrm{Na}^{+} / \mathrm{H}^{+}$translocation stoichiometry is not represented in the figure. FwdA-F/FmdA-F: formylmethanofuran dehydrogenase, Ftr: formylmethanofurantetrahydromethanopterin formyl-transferase, Mch: methenyltetrahydromethanopterin cyclohydrolase, Mtd: methylenetetrahydromethanopterin dehydrogenase, Mer: 5,10methylenetetrahydromethanopterin reductase, MtrA-H:

Msp_1442 and Msp_1436) (Fricke et al. 2006). Moreover, two soluble $\mathrm{HdrABC}$ complexes are encoded in the genome (HdrA1B1C1: Msp_1476 and Msp_1013/4; HdrA2B2C2: Msp_0125-7). It is assumed that a soluble hydrogenase/ heterodisulfide reductase complex (MvhADG/HdrABC) is used in the organism to transfer the electrons resulting from $\mathrm{H}_{2}$ oxidation by MvhADG to the reduction of heterodisulfide and ferredoxin by HdrABC (Fricke et al. 2006; Thauer et al. 2008). The reduced ferredoxin then could be reoxidized by the membrane-bound Ehb complex resulting in a sodium motive force (Thauer et al. 2008). The membrane-bound Mtr complex tetrahydromethanopterin S-methyl-transferase, McrABCDG methylcoenzyme $\mathrm{M}$ reductase, FrhABG: coenzyme $\mathrm{F}_{420}$-reducing hydrogenase, HdrABC: soluble heterodisulfide reductase, MvhAGD: $\mathrm{F}_{420}$-non-reducing hydrogenase, FdhABI: formate dehydrogenase (FdhI contains a btype heme), FpoA-O: $\mathrm{F}_{420} \mathrm{H}_{2}$ dehydrogenase, HdrDE: membrane bound heterodisulfide reductase, EhbA-Q: energy-conserving hydrogenase, VhtGACD: [NiFe]-hydrogenase, HyaAB: $\mathrm{H}_{2}$-producing hydrogenase, $4 \mathrm{~g}$ Hyd: 4 g-type hydrogenase, ATPase: ATP synthase, MTI and MTII: methyltransferase, CoB: coenzyme B, CoM: coenzyme M, $\mathrm{H}_{4}$ MPT: tetrahydromethanopterin, MFR: methanofuran, Fd: ferredoxin, $\mathrm{F}_{420} \mathrm{H}_{2}$ : reduced coenzyme $\mathrm{F}_{420}$, MP: methanophenazine, $\mathrm{CO}(\mathrm{III})$ : cobalamin binding protein.

does not contribute to energy conservation in $M$. stadtmanae. Interestingly, a different phylotype of Methanosphaera isolated from the kangaroo foregut was capable of reducing methanol with ethanol as the electron donor, in the absence of hydrogen (Hoedt et al. 2016). Methanogenesis from ethanol alone was not observed. The genome of Methanosphaera sp. WGK6 encodes alcohol and aldehyde dehydrogenases that provide electrons for the reduction of methanol to methane. How this metabolism is coupled with energy conservation remains to be elucidated. 


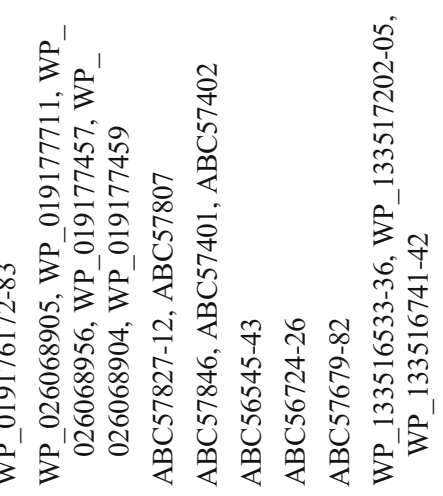

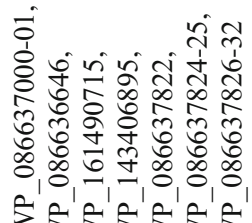

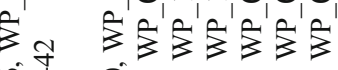

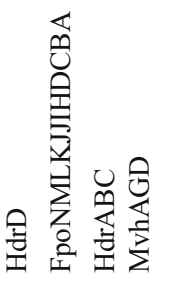

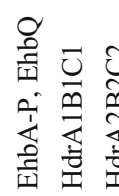
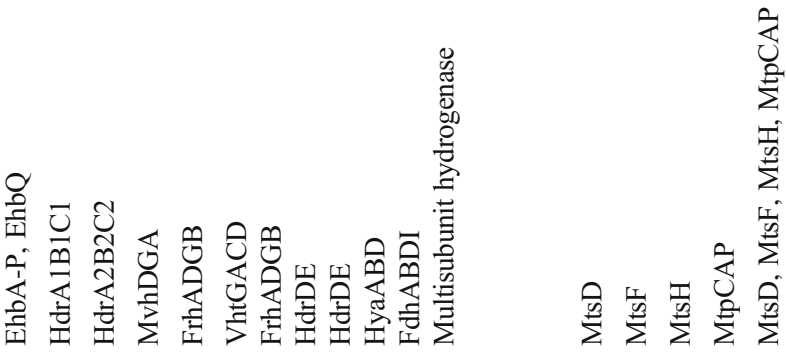

否
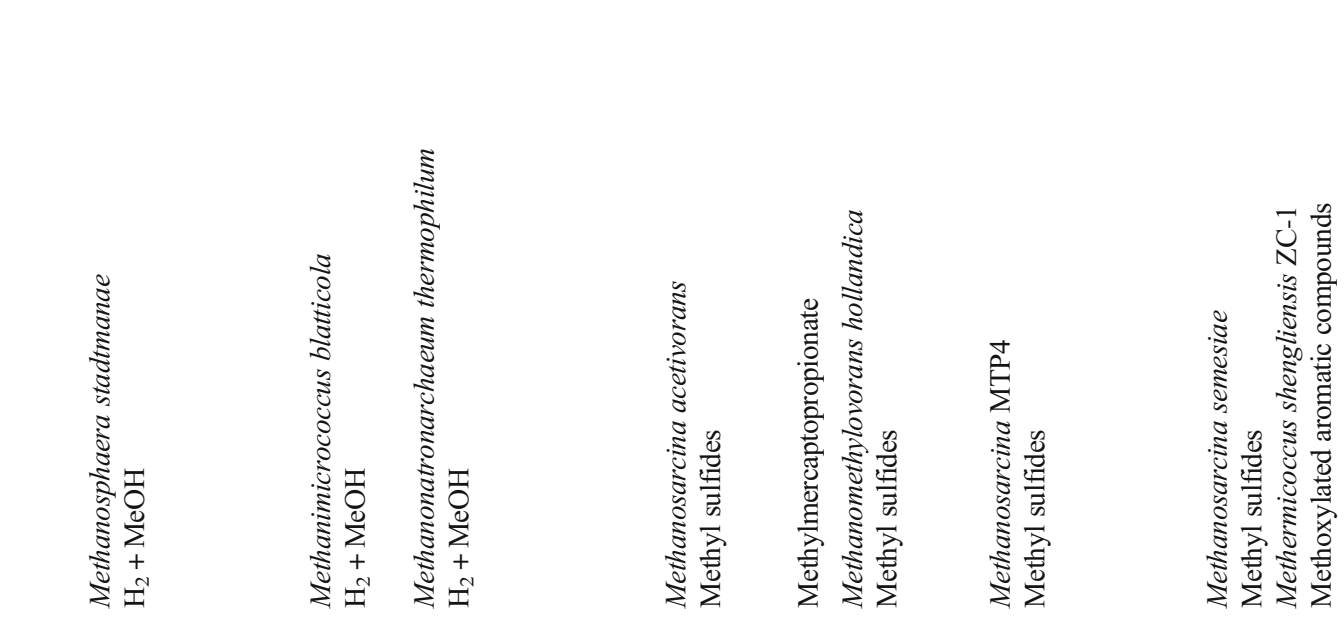
M. luminyensis was isolated from human feces and was found to only produce methane when both hydrogen and methanol were present (Dridi et al. 2012). It is phylogenetically distant from other methanogens and affiliated with the Thermoplasmatales. Next to methanol Methanomassiliicoccales can also reduce methylamines in the presence of hydrogen (Lang et al. 2015). In contrast to $M$. stadtmanae, the $M$. luminyensis genome lacks the entire pathway for $\mathrm{CO}_{2}$ reduction to methyl coenzyme $\mathrm{M}$ (Gorlas et al. 2012). In contrast to hydrogenotrophic methanogens $M$. luminyensis does not possess the energy-conserving methyltransferase (MtrA-H) to generate a sodium motive force and contrary to methylotrophic methanogens it does not produce cytochromes for energy conservation. Instead, Methanomassiliicoccales possess a $\mathrm{F}_{420}$ :methanophenazine oxidoreductase (Fpo) which lacks the $\mathrm{F}_{420}$-oxidizing subunit FpoF comparable to the ferredoxin-dependent Fpo-like homo$\log$ in Methanothrix thermoacetophila (Welte and Deppenmeier 2011). Moreover, Methanomassiliicoccales also lack the subunit HdrE of the membrane-bound heterodisulfide reductase $\mathrm{HdrDE}$ (Fig. 4C, Table 1). Therefore, it is assumed that in those organisms the Fpo-like complex interacts directly with subunit $\mathrm{HdrD}$, forming an energy-converting ferredoxin:heterodisulfide oxidoreductase (Lang et al. 2015). Both heterodisulfide reductases HdrABC and $\mathrm{HdrD}$ as well as the "headless" ferredoxin-dependent $\mathrm{F}_{420}$ :methanophenazine oxidoreductase Fpo are highly transcribed in M. luminyensis (Kröninger et al. 2016). In addition, the activity of the HdrABC/MvhADG complex and of $\mathrm{HdrD}$ was measured. It is proposed that the membrane-bound electron transfer is based on the conversion of two molecules of methanol resulting in the formation of two molecules of the heterodisulfide (Kröninger et al. 2016). The HdrABC/ MvhADG complex catalyzes the $\mathrm{H}_{2}$-dependent reduction of heterodisulfide and the formation of reduced ferredoxin. The reduced ferredoxin is then oxidized by the 'headless' Fpo complex thereby translocating up to $4 \mathrm{H}^{+}$across the membrane and electrons are channeled to $\mathrm{HdrD}$ for reduction of the second heterodisulfide (Kröninger et al. 2019). Interestingly, protons instead of $\mathrm{Na}^{+}$ions are used as coupling ions for the generation of the electrochemical ion gradient in Methanomassiliicoccus.

Also, members of the Methanonatronarchaeales like Methanonatronarchaeum thermophilum have been shown to utilize $\mathrm{C}_{1}$ methylated compounds as electron acceptors and $\mathrm{H}_{2}$ or formate as electron donors (Sorokin et al. 2017, 2018). They are extremely halophilic methanogens affiliated with a new methanogenic class, the Methanonatronarchaeia. Although some of the enzymes that are part of the oxidative branch of methanogenesis from the methyl group to $\mathrm{CO}_{2}$ are encoded in the genome of the organism ( $m e r, m t d, m c h, f t r)$, other enzymes essential for this pathway like Mtr and Fwd are not encoded in the genome. The question of the physiological 
role of those remaining genes rises as the absence of the methyltransferase Mtr disconnects the methyl reducing pathway to methane from the oxidative branch of methanogenesis to $\mathrm{CO}_{2}$ (Fig. 4D; Ferrer et al. 2018). Sorokin et al. (2017) report a metabolic model based on genome reconstruction, suggesting that energy conservation is performed via a membrane-bound respiratory chain: membrane-bound hydrogenase (or formate dehydrogenase) acts as electron input module, and electrons are transferred to methanophenazine. The membrane-bound heterodisulfide reductase $\mathrm{HdrDE}$ acts as a terminal reductase and reduces the CoM-S-S-CoB heterodisulfide. Interestingly, this respiratory chain contains cytochromes, which were previously only found in the Methanosarcinales within the methanogens. In the current reconstruction of the metabolic model, it is unclear how electrons are transferred from methanogenesis to anabolic reactions, as cytoplasmic hydrogenases are absent and no enzymes for reduction of $F_{420}$, ferredoxin or $\mathrm{NAD}(\mathrm{P})^{+}$have been detected. Intriguingly, we identified a gene cluster encoding proteins related to membrane-bound NADH dehydrogenase subunits (AMET1_RS07305 to AMET1_RS07375).. Methanogens encode multisubunit membrane-bound hydrogenases, also distantly related to NADH dehydrogenases, termed Eha, Ehb, or Ech, classified as group $4 \mathrm{~h}, 4 \mathrm{i}$, and $4 \mathrm{e}$ hydrogenases, respectively, according to Søndergaard et al. (2016). They have a role in anaplerotic reactions to provide low-potential electrons with $\mathrm{H}_{2}$ as an electron donor (Eha, Ehb, Major et al. 2010; Lie et al. 2012) or in ferredoxin-dependent energy conservation (Welte et al. 2010). According to HydDB (Søndergaard et al. 2016), the putative multisubunit hydrogenase of Methanonatronarchaeum is classified as group $4 \mathrm{~g}$ hydrogenase for which no experimental data are available.
Our analysis suggests that this class $4 \mathrm{~g}$ membrane-bound hydrogenase is involved in providing low-potential electrons for anabolism and provides the missing link between catabolism and anabolism. This hypothesis needs to be addressed by future biochemical and physiological experiments.

Next to the previously described methanogens specialized in $\mathrm{H}_{2}$-dependent methylotrophic growth, there are also versatile methanogens that can additionally grow on hydrogen and methanol as, e.g., Methanosarcina barkeri. M. barkeri has been shown to consume hydrogen and methanol in equimolar amounts for energy conservation and is under these growth conditions dependent on acetate for anabolism (Mueller et al. 1986).

\section{Use of methylated sulfur compounds as substrates for methanogenesis}

Methanethiol (MT) and dimethyl sulfide (DMS) are the dominant volatile organic sulfur compounds in freshwater sediments. In these habitats, DMS and MT formation mainly occur through sulfide methylation by anaerobic O-demethylation of methoxylated aromatic compounds (Bak et al. 1992; Lomans et al. 2001, 2002). The major part of the produced MT and DMS is degraded anaerobically by methanogens (Lomans et al. 1999b, c, 2002). Using methylated sulfur compounds for methanogenesis is energetically less favorable than using methanol as a substrate (Table 2). Methanomethylovorans hollandica strain DMS1T has been isolated from freshwater sediments on DMS and found to use methanol, methylamines, MT, and DMS as substrates (Lomans et al. 1999a). Methanogens like strain DMS1T can also be involved in the formation of DMS through methylation of MT as the DMS conversion is reversible (Lomans et al. 1999a). Another

Table 2 Gibbs free energy values for different methanogenesis substrates

\begin{tabular}{|c|c|c|}
\hline Substrate & Reaction equation & $\Delta \mathrm{G}^{\prime \circ}\left(\mathrm{kJ} / \mathrm{mol} \mathrm{CH}_{4}\right)$ \\
\hline $\mathrm{H}_{2}+\mathrm{CO}_{2}$ & $4 \mathrm{H}_{2}+\mathrm{CO}_{2} \rightarrow \mathrm{CH}_{4}+2 \mathrm{H}_{2} \mathrm{O}$ & -131 (a) \\
\hline $\mathrm{HCOO}^{-}$ & $4 \mathrm{HCOO}^{-}+4 \mathrm{H}^{+} \rightarrow \mathrm{CH}_{4}+3 \mathrm{CO}_{2}+2 \mathrm{H}_{2} \mathrm{O}$ & $-145(a)$ \\
\hline $\mathrm{CH}_{3} \mathrm{CH}_{2} \mathrm{OH}+\mathrm{CO}_{2}$ & $2 \mathrm{CH}_{3} \mathrm{CH}_{2} \mathrm{OH}+\mathrm{CO}_{2} \rightarrow 2 \mathrm{CH}_{3} \mathrm{COOH}+\mathrm{CH}_{4}$ & $-121(\mathrm{e})$ \\
\hline $\mathrm{H}_{2}+\mathrm{CH}_{3} \mathrm{OH}$ & $\mathrm{CH}_{3} \mathrm{OH}+\mathrm{H}_{2} \rightarrow \mathrm{CH}_{4}+\mathrm{H}_{2} \mathrm{O}$ & $-113(\mathrm{e})$ \\
\hline $\mathrm{CH}_{3} \mathrm{OH}+\mathrm{CH}_{3} \mathrm{CH}_{2} \mathrm{OH}$ & $2 \mathrm{CH}_{3} \mathrm{OH}+\mathrm{CH}_{3} \mathrm{CH}_{2} \mathrm{OH} \rightarrow 2 \mathrm{CH}_{4}+\mathrm{H}_{2} \mathrm{O}+\mathrm{CH}_{3} \mathrm{COOH}$ & $-100(b)$ \\
\hline $\mathrm{CH}_{3} \mathrm{CHOHCH}_{3}+\mathrm{CO}_{2}$ & $4 \mathrm{CH}_{3} \mathrm{CHOHCH}_{3}+\mathrm{HCO}_{3}+\mathrm{H}^{+} \rightarrow 4 \mathrm{CH}_{3} \mathrm{COCH}_{3}+\mathrm{CH}_{4}+3 \mathrm{H}_{2} \mathrm{O}$ & $-37(\mathrm{c})$ \\
\hline $\mathrm{CH}_{3} \mathrm{OH}$ & $4 \mathrm{CH}_{3} \mathrm{OH} \rightarrow \mathrm{CO}_{2}+3 \mathrm{CH}_{4}+2 \mathrm{H}_{2} \mathrm{O}$ & -107 (a) \\
\hline $\mathrm{CH}_{3}-\mathrm{COOH}$ & $\mathrm{CH}_{3} \mathrm{COOH} \rightarrow \mathrm{CO}_{2}+\mathrm{CH}_{4}$ & $-36(a)$ \\
\hline $\mathrm{CH}_{3}-\mathrm{SH}\left(\mathrm{CH}_{3}-\mathrm{S}-\mathrm{R}\right)$ & $4 \mathrm{CH}_{3} \mathrm{SH}+3 \mathrm{H}_{2} \mathrm{O} \rightarrow 3 \mathrm{CH}_{4}+\mathrm{HCO}_{3}^{-}+4 \mathrm{HS}^{-}+5 \mathrm{H}^{+}$ & -49 (b) \\
\hline Betaine $\left(\mathrm{CH}_{3}-\mathrm{N}-\mathrm{R}\right)$ & $4\left(\mathrm{CH}_{3}\right)_{3} \mathrm{~N}^{+} \mathrm{CH}_{2} \mathrm{COO}^{-}+2 \mathrm{H}_{2} \mathrm{O} \rightarrow 4\left(\mathrm{CH}_{3}\right)_{2} \mathrm{~N}^{+} \mathrm{CH}_{2} \mathrm{COO}^{-}+3 \mathrm{CH}_{4}+\mathrm{CO}_{2}$ & $-241(\mathrm{c})$ \\
\hline Choline $\left(\mathrm{CH}_{3}-\mathrm{N}-\mathrm{R}\right)$ & $4\left(\mathrm{CH}_{3}\right)_{3} \mathrm{~N}^{+} \mathrm{CH}_{2} \mathrm{CH}_{2} \mathrm{OH}+6 \mathrm{H}_{2} \mathrm{O} \rightarrow 4 \mathrm{H}_{2} \mathrm{NCH}_{2} \mathrm{CH}_{2} \mathrm{OH}+9 \mathrm{CH}_{4}+3 \mathrm{CO}_{2}+4 \mathrm{H}^{+}$ & $-63(d)$ \\
\hline Trimethylamine $\left(\mathrm{CH}_{3}-\mathrm{N}-\mathrm{R}\right)$ & $4\left(\mathrm{CH}_{3}\right)_{3} \mathrm{~N}+6 \mathrm{H}_{2} \mathrm{O}+4 \mathrm{H}^{+} \rightarrow 4 \mathrm{NH}_{4}^{+}+9 \mathrm{CH}_{4}+3 \mathrm{CO}_{2}$ & $-31(\mathrm{~d})$ \\
\hline 2-methoxyphenol $\left(\mathrm{CH}_{3}-\mathrm{O}-\mathrm{R}\right)$ & 4 2-methoxyphenol $+2 \mathrm{H}_{2} \mathrm{O} \rightarrow 4$ 2-hydroxyphenol $+\mathrm{CO}_{2}+3 \mathrm{CH}_{4}$ & $-90(f)$ \\
\hline
\end{tabular}

The values for the standard free energy change $\left(\Delta \mathrm{G}^{\circ}\right.$ ) are derived from (a) (Thauer 1998), (b) (Finster et al. 1992), (c) (Watkins et al. 2014), (d) (Watkins et al. 2012). (e) are values calculated by the webtool eQuilibrator (Flamholz et al. 2012) and (f) gives values calculated by use of the standard free energies of formation at $25^{\circ} \mathrm{C}$ 
methanogen that is able to use DMS and methanethiol as substrates for methanogenesis is Methanosarcina semesiae MD1T which has been isolated from mangrove sediment (Lyimo et al. 2000). In the marine environment, DMS is the most important volatile sulfur compound and originates mainly from the algal osmolyte dimethylsulfoniopropionate (DMSP) (van der Maarel and $\mathrm{Hansen} 1997$ ). Next to DMS also methylmercaptopropionate (MMPA) is a conversion product of DMSP in anoxic marine sediments. An example of a marine DMS degrader is the methanogen Methanosarcina sp. strain MTP4 which is able to use DMS as sole source of energy (Finster et al. 1992). Furthermore, it has been described for anoxic aquatic sediments that methanogens and sulfate reducers compete for DMS when it is present at low concentrations (Kiene et al. 1986; Lyimo et al. 2009) and that methanogens are the main DMS converters at high DMS concentrations (Kiene et al. 1986), whereby MT is a transient intermediate of DMS metabolism. The methylated sulfur compound MMPA that is present in the marine environment has been shown to be demethylated to mercaptopropionate and methane by three marine Methanosarcina strains (van der Maarel and Hansen 1997). The specific mechanism of methyl transfer from methylated sulfur compounds and the transfer into the methanogenesis pathways has not been studied for the methanogens mentioned above. In methylotrophic methanogens, the methyl group from methylated compounds like methanol is channeled into the methanogenesis pathway via transfer from the substrate to coenzyme M (CoM) (Fig. 5). It has been shown for Methanosarcina barkeri, a very versatile methanogen using hydrogenotrophic, methylotrophic, and aceticlastic methanogenesis, that this organism can convert DMS and MMPA to methane when grown on acetate (Paul and Krzycki 1996; Tallant and Krzycki 1996, 1997). For this organism, it has been demonstrated that a $30-\mathrm{kDa}$ corrinoid protein (MtsB) and a 41-kDa protein (MtsA), forming a $480 \mathrm{kDa}$ complex, are used for coenzyme M methylation by methylated thiols (Paul and Krzycki 1996; Tallant and Krzycki 1996, 1997). A closely related methanogen, Methanosarcina acetivorans, has been shown to be able to use DMS as the sole energy source and specific methyltransferases, called MtsD, MtsF, and MtsH (MA0859, MA4384, and MA4558) could be associated with the ability to grow on methyl sulfides (Oelgeschläger and Rother 2009a, b). Further analysis of those methyltransferases revealed that the preferred substrate for MtsD is DMS, while the preferred substrate for MtsF is methanethiol and $\mathrm{MtsH}$ appears to accept both substrates (Fu and Metcalf 2015). Interestingly, all three M. acetivorans proteins retrieve the Methanomethylovorans hollandica best BLAST hit METHO-RS06035 indicating that this protein might accept both methanethiol and DMS as substrates. Moreover, it has been shown that a four-gene locus, $m t p C A P$ $m s r H$, is required for growth on MMPA in $M$. acetivorans $(\mathrm{Fu}$ and Metcalf 2015). MtpC, $m t p A$, and $m t p P$ encode a putative corrinoid protein, a coenzyme $\mathrm{M}$ methyltransferase, and a major facilitator superfamily transporter, while $m s r H$ encodes a putative transcriptional regulator.
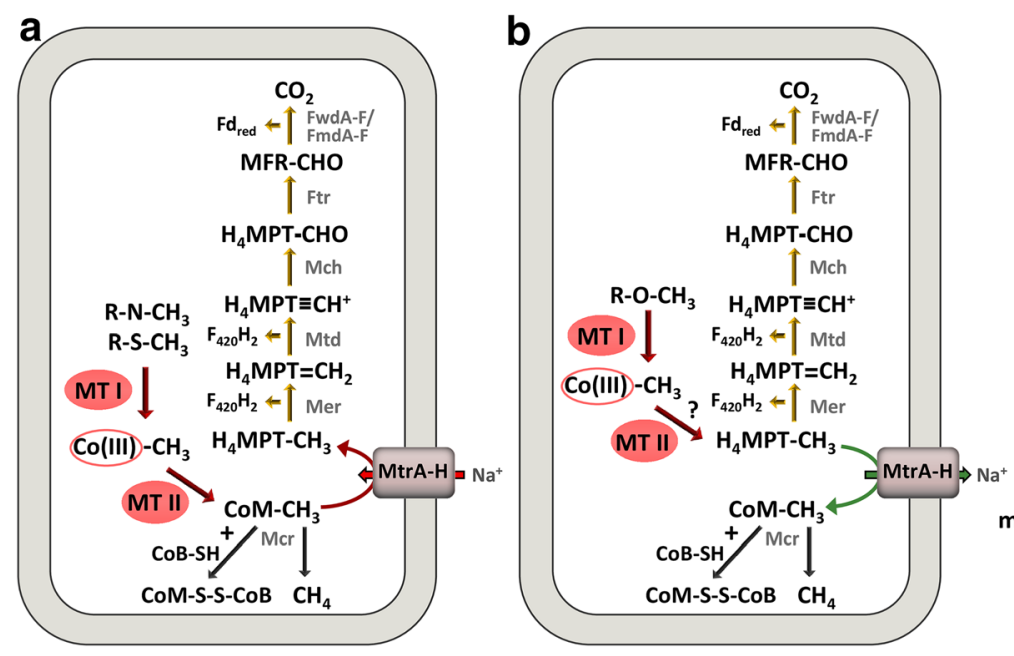

C

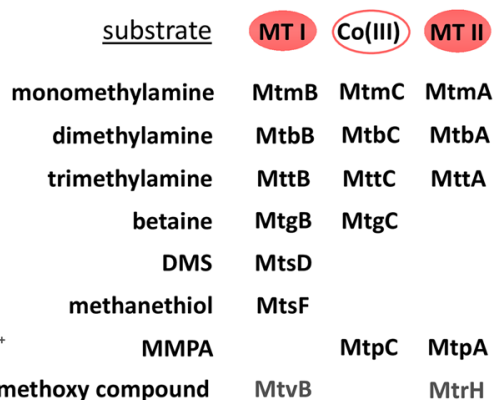

Fig. 5 Methanogenesis from methylated sulfur compounds or tertiary and quaternary amines (a) and from methoxylated aromatic compounds in Methermicoccus shengliensis (b). Panel $\mathbf{c}$ shows the proteins that are involved in methyl transfer for diverse substrates. The question mark indicates that there is no biochemical evidence yet if the methyl group is transferred to $\mathrm{H}_{4} \mathrm{MPT}$ or CoM during growth on methoxy compounds. For growth on methoxy compounds proteins similar to the $\mathrm{O}$ demethylase MtvB and the methyltransferase MtrH are most likely involved in the methyl transfer. Some methanogens use a $\mathrm{H}_{4}$ MPT derivative called tetrahydrosarcinopterin $\left(\mathrm{H}_{4} \mathrm{SPT}\right)$. The $\mathrm{Na}^{+} / \mathrm{H}^{+}$translocation stoichiometry is not represented in the figure. FwdA-F/FmdA-F: formylmethanofuran dehydrogenase, Ftr: formylmethanofurantetrahydromethanopterin formyl-transferase, Mch: methenyltetrahydromethanopterin cyclohydrolase, Mtd: methylenetetrahydromethanopterin dehydrogenase, Mer: 5,10methylenetetrahydromethanopterin reductase, MtrA-H: tetrahydromethanopterin S-methyl-transferase, McrABCDG methylcoenzyme M reductase, MTI, and MTII: methyltransferase, CoB: coenzyme B, CoM: coenzyme M, $\mathrm{H}_{4} \mathrm{MPT}$ : tetrahydromethanopterin, MFR: methanofuran, $\mathrm{CO}(\mathrm{III})$ : cobalamin binding protein, $\mathrm{MtrH}$ : tetrahydromethanopterin S-methyltransferase subunit $\mathrm{H}$ 


\section{Methanogenesis from methoxylated aromatic compounds}

Methoxylated compounds are derived from lignin and occur in large quantities on earth (De Leeuw and Largeau 1993). For a long time, it has been known that methoxylated aromatic compounds can be converted to methane by anaerobic microorganisms (Healy and Young 1979). Acetogenic bacteria were the first anaerobes discovered to use methoxylated aromatic compounds for energy conservation (Bache and Pfennig 1981) via conversion of the methyl group to acetate in the acetyl-CoA (Wood-Ljungdahl) pathway. One example is Parasporobacterium paucivorans that has been shown to produce MT, DMS, acetate, and butyrate from the methoxylated aromatic compound syringate (Lomans et al. 2001). However, it has recently been discovered that methanogens are also capable of using methoxylated aromatic compounds as substrate: the methanogen Methermicoccus shengliensis has been shown to be able to use a large variety of methoxylated aromatic compounds as substrates for methane generation termed methoxydotrophic methanogenesis (Mayumi et al. 2016). In contrast to acetogenic bacteria $M$. shengliensis is so far the only archaeon able to grow on methoxylated aromatic compounds. $M$. shengliensis ZC-1 was isolated from the Shengli oil field (China) and has been shown to use either methylated compounds like methanol (Cheng et al. 2007) or a large variety of methoxylated aromatic compounds (Mayumi et al. 2016) for growth. It was observed that during the growth of the organism the concentration of the methoxylated aromatic compound decreases while the concentration of the hydroxylated version of this compound increases, and $\mathrm{CO}_{2}$ and $\mathrm{CH}_{4}$ are formed. The exact metabolic pathway for growth on methoxy compounds is not known for methanogens so far. For acetogens, it is wellknown that they use two methyltransferases, one corrinoid protein and one activating enzyme that recycles the corrinoid protein for transfer of the methyl group from methoxylated compounds (Kaufmann et al. 1997). Also, M. shengliensis features one gene cluster encoding two O-demethylases (Amam_00018/BP07_RS03255;Amam_00019/ BP07_RS03250) similar to those of acetogens that might demethoxylate the methoxy compound and transfer the methyl group from the methoxy group to a cobalt-containing corrinoid protein (Fig. 5; Amam 00017/BP07_RS03260). The methyltransferase that shuttles the methyl group from the corrinoid protein into the methanogenesis pathway might be an MtrHlike methyltransferase (Amam_00021/BP07_RS03240), which is encoded in the same gene cluster as the O-demethylases, the corrinoid protein and the respective corrinoid activation protein (Amam 00022/BP07 RS03235). In contrast to growth on methanol, the methyl group is most likely transferred to tetrahydromethanopterin instead of coenzyme $\mathrm{M}$ by this methyltransferase (Kurth et al. unpublished results). Also, several transporters are encoded in that gene cluster that might be involved in the transport of the methoxylated aromatic compound into the cell and export of the hydroxylated aromatic compound.

\section{Methanogenesis from tertiary and quaternary amines}

Choline ( $N, N, N$-trimethylethanolamine) is a compound that is widely distributed in membrane lipids and has been shown to be used as a substrate for methanogenesis with ethanolamine as a product by five Methanococcoides strains (Watkins et al. 2012). Di- and monomethylethanolamine are metabolic intermediates in this pathway that temporarily accumulate. Both have also been shown to be a substrate for methanogenesis. Also, Methanococcoides vulcani, a marine methylotrophic methanogen isolated from a mud volcano, has been shown to use betaine, choline, and $N, N$-dimethylethanolamine for methanogenesis (L'Haridon et al. 2014). However, not all Methanococcoides strains can utilize choline (Watkins et al. 2012). Later on, it has also been shown that some marine Methanococcoides strains can use betaine $(N, N, N$ trimethylglycine) as a substrate for methanogenesis, partially demethylating it to $N, N$-dimethylglycine (Watkins et al. 2014). In contrast, $N, N$-dimethylglycine or sarcosine ( $N$-methylglycine) could not be used as substrates in methanogenesis. Growth rates and yields during growth on betaine were similar to those with trimethylamine. However, betaine is only partially demethylated indicating that the yield per methyl group is significantly higher than with trimethylamine (Watkins et al. 2014). A tetramethylammonium-degrading methanogen (strain NaT1) was isolated from a sand sample obtained from Tokyo Bay (Tanaka 1994). Two further methanogen strains with the ability to utilize quaternary amines were isolated from an estuarine sediment (Ticak et al. 2015). Strain B1d is closely related to Methanolobus vulcani PL-12/MT and strain Q3c to Methanococcoides sp. PM1 and PM2. Strain Q3c was able to grow on tetramethylammonium and choline, while strain B1d was able to grow on betaine. B1d is the first quaternary amineutilizing methanogen from the genus Methanolobus (Ticak et al. 2015). In conclusion, quaternary amines may serve as substrates for methanogenesis in marine environments.

The transport of quaternary amines is proposed to proceed via a betaine/choline/carnitine transporter (BCCT) or a homo$\log$ of the predicted trimethylamine permease (MttP) seen in other sequenced methylamine-utilizing methanogens (Ticak et al. 2015). Moreover, for quaternary amines like trimethylammonium, it is known that they are demethylated by a three-component enzyme system including a substratespecific methyltransferase, a corrinoid-binding protein, and a CoM methyltransferase (Fig. 5; Asakawa et al. 1998; Ferguson et al. 2000). Next to the three-component methyltransferase systems for monomethylamine (MtmBCA), dimethylamine (MtbBCA) and trimethylamine (MttBCA) it has been described for M. barkeri that RamA, a $60-\mathrm{kDa}$ 
monomeric ironsulfur protein, is required for ATP-dependent reductive activation of methylamine:CoM methyl transfer from all three methylamines (Ferguson et al. 2009). For the betaine consuming methanogen Methanolobus vulcani B1d it has been shown that the organism possesses the methyltransferase MtgB (FKV42_RS08545) that catalyzes betainedependent methylation of free cob(I)alamin (Creighbaum et al. 2019). Further, proteomic analysis revealed that MtgB, a corrinoid binding protein (FKV42_RS08550), a corrinoid reductive activation enzyme (FKV42_RS10455) and a methylcorrinoid:CoM methyltransferase (FKV42_RS10480) were highly abundant when $M$. vulcani B1d was grown on betaine relative to growth on trimethylamine. Energy conservation presumably follows what is known for methylamine or methanol dependent growth, using a membrane-bound respiratory chain involving Ech + Vho or Rnf and membranebound heterodisulfide reductase HdrDE.

\section{Conclusion}

This review comprises an overview of unconventional substrates and pathways used by methanogenic archaea. Next to describing the involved organisms we mainly elaborated on the features of the different metabolic pathways focusing on the involved genes and enzymes. With the help of this overview and the compiled bioinformatic information, we provide helpful information for further research on different methanogenic pathways. For example, the key enzymes of the secondary alcohol metabolism of various methanogens, an iron depending alcohol dehydrogenase, has so far only been described bioinformatically but not biochemically. In addition, also the $\mathrm{H}_{2}$-dependent methylotrophic methanogenesis pathways of Methanimicrococcus blatticola and Methanonatronarchaea have not been studied so far. Bioinformatic analysis revealed that next to a membrane-bound heterodisulfide reductase, a methanophenazine-reducing hydrogenase in the case of Methanimicrococcus blatticola and a membrane-bound multisubunit hydrogenase in case of Methanonatronarchaeum thermophilum might be involved. However, this hypothesis still has to be proven. Moreover, the methyltransferase systems of methanogens using methylated sulfur compounds or tertiary and quaternary amines as substrates should be studied in more detail especially in view of substrate specificities of the involved enzymes. Another interesting research topic is the methanogenesis from methoxylated aromatic compounds. So far only the methanogen Methermicoccus shengliensis has been shown to make methane from those compounds. Nevertheless, the metabolic pathway of this organism has not yet been described in detail. In summary, we highlighted that there is potential for further research on the methanogenesis pathways mentioned in this review and for discovering further methanogenesis pathways on unconventional substrates.
Authors' contributions $\mathrm{JK}$, HOdC, and $\mathrm{CW}$ designed the mini-review project and wrote the manuscript.

Funding information JK was supported by the Deutsche Forschungsgesellschaft (DFG) Grant KU 3768/1-1; HOdC by the European Research Council Advanced Grant VOLCANO (669371) and $\mathrm{CW}$ by the Soehngen Institute of Anaerobic Microbiology Gravitation Grant 024.002.002.

Data availability Not applicable

\section{Compliance with ethical standards}

Conflict of interest The authors declare that they have no conflict of interest.

Ethics statement This article does not contain any studies with human participants or animals performed by any of the authors.

Code availability Not applicable

Open Access This article is licensed under a Creative Commons Attribution 4.0 International License, which permits use, sharing, adaptation, distribution and reproduction in any medium or format, as long as you give appropriate credit to the original author(s) and the source, provide a link to the Creative Commons licence, and indicate if changes were made. The images or other third party material in this article are included in the article's Creative Commons licence, unless indicated otherwise in a credit line to the material. If material is not included in the article's Creative Commons licence and your intended use is not permitted by statutory regulation or exceeds the permitted use, you will need to obtain permission directly from the copyright holder. To view a copy of this licence, visit http://creativecommons.org/licenses/by/4.0/.

\section{References}

Asakawa S, Sauer K, Liesack W, Tauer RK (1998) Tetramethylammonium:coenzyme $\mathrm{M}$ methyltransferase system from Methanococcoides sp. Arch Microbiol 170:220-226

Bache R, Pfennig N (1981) Selective isolation of Acetobacterium woodit on methoxylated aromatic acids and determination of growth yields. Arch Microbiol 130:255-261

Bak F, Finster K, Rothfuss F (1992) Formation of dimethylsulfide and methanethiol from methoxylated aromatic compounds and inorganic sulfide by newly isolated anaerobic bacteria. Arch Microbiol 157 : 529-534

Berger S, Welte C, Deppenmeier U (2012) Acetate activation in Methanosaeta thermophila: characterization of the key enzymes pyrophosphatase and acetyl-CoA synthetase. Archaea 2012:315153

Bond DR, Lovley DR (2002) Reduction of Fe(III) oxide by methanogens in the presence and absence of extracellular quinones. Environ Microbiol 4:115-124

Cheng L, Qiu TL, Yin XB, Wu XL, Hu GQ, Deng Y, Zhang H (2007) Methermicoccus shengliensis gen. nov., sp. nov., a thermophilic, methylotrophc methanogen isolated from oil-production water, and proposal of Methermicoccaceae fam. nov. Int J Syst Evol Microbiol 57:2964-2969

Conrad R (2009) The global methane cycle: recent advances in understanding the microbial processes involved. Environ Microbiol Rep 1:285-292 
Costa KC, Wong PM, Wang T, Lie TJ, Dodsworth JA, Swanson I, Burn JA, Hackett M, Leigh JA (2010) Protein complexing in a methanogen suggests electron bifurcation and electron delivery from formate to heterodisulfide reductase. Proc Natl Acad Sci U S A 107:11050-11055

Creighbaum AJ, Ticak T, Shinde S, Wang X, Ferguson DJ (2019) Examination of the glycine betaine-dependent methylotrophic methanogenesis pathway: insights into anaerobic quaternary amine methylotrophy. Front Microbiol 10:2572

De Leeuw JW, Largeau C (1993) A review of macromolecular organic compounds that comprise living organisms and their role in kerogen, coal, and petroleum formation. In: Engel MH, Macko SA (eds) Organic geochemistry, Topics in Geobiology, vol 11. Springer, Boston, pp 23-72

Dridi B, Fardeau M-L, Ollivier B, Raoult D, Drancourt M (2012) Methanomassiliicoccus luminyensis gen. nov., sp. nov., a methanogenic archaeon isolated from human faeces. Int J Syst Evol Microbiol 62:1902-1907

Enzmann F, Mayer F, Rother M, Holtmann D (2018) Methanogens: biochemical background and biotechnological applications. AMB Express 8:1-22

Ferguson DJ, Gorlatova N, Grahame DA, Krzycki JA (2000) Reconstitution of dimethylamine:coenzyme $\mathrm{M}$ methyl transfer with a discrete corrinoid protein and two methyltransferases purified from Methanosarcina barkeri. J Biol Chem 275:29053-29060

Ferguson T, Soares JA, Lienard T, Gottschalk G, Krzycki JA (2009) RamA, a protein required for reductive activation of corrinoiddependent methylamine methyltransferase reactions in methanogenic archaea. J Biol Chem 284:2285-2295

Ferrer M, Sorokin DY, Wolf YI, Ciordia S, Mena MC, Bargiela R, Koonin EV, Makarova KS (2018) Proteomic analysis of Methanonatronarchaeum thermophilum AMET1, a representative of a putative new class of euryarchaeota, "Methanonatronarchaeia.". Genes (Basel) 9(2):E28

Finster K, Tanimoto Y, Bak F (1992) Fermentation of methanethiol and dimethylsulfide by a newly isolated methanogenic bacterium. Arch Microbiol 157:425-430

Flamholz A, Noor E, Bar-Even A, Milo R (2012) eQuilibrator - the biochemical thermodynamics calculator. Nucleic Acids Res 40: D770-D775

Fricke WF, Seedorf H, Henne A, Krüer M, Liesegang H, Hedderich R, Gottschalk G, Thauer RK (2006) The genome sequence of Methanosphaera stadtmanae reveals why this human intestinal archaeon is restricted to methanol and $\mathrm{H} 2$ for methane formation and ATP synthesis. J Bacteriol 188:642-658

Fu H, Metcalf WW (2015) Genetic basis for metabolism of methylated sulfur compounds in Methanosarcina species. J Bacteriol 197: $1515-1524$

Gorlas A, Robert C, Gimenez G, Drancourt M, Raoult D (2012) Complete genome sequence of Methanomassiliicoccus luminyensis, the largest genome of a human-associated Archaea species. J Bacteriol 194(17):4745

Gunsalus RP, Cook LE, Crable B, Rohlin L, McDonald E, Mouttaki H, Sieber JR, Poweleit N, Zhou H, Lapidus AL, Daligault HE, Land M, Gilna P, Ivanova N, Kyrpides N, Culley DE, McInerney MJ (2016) Complete genome sequence of Methanospirillum hungatei type strain JF1. Stand Genomic Sci 11:2

Healy JB, Young LY (1979) Anaerobic biodegradation of eleven aromatic compounds to methane. Appl Environ Microbiol 38:84-89

Hoedt EC, Cuív P, Evans PN, Smith WJM, McSweeney CS, Denman SE, Morrison M (2016) Differences down-under: alcohol-fueled methanogenesis by archaea present in Australian macropodids. ISME J 10:2376-2388

Imachi H, Sakai S, Nagai H, Yamaguchi T, Takai K (2009) Methanofollis ethanolicus sp. nov., an ethanol-utilizing methanogen isolated from a lotus field. Int J Syst Evol Microbiol 59:800-805
Jones JB, Stadtman TC (1979) Reconstitution of a formate-NADP+ oxidoreductase from formate dehydrogenase and a 5-Deazaflavinlinked NADP+ reductase isolated from Methanococcus vannielii. J Biol Chem 255:1049-1053

Kaster A, Moll J, Parey K, Thauer RK (2011) Coupling of ferredoxin and heterodisulfide reduction via electron bifurcation in hydrogenotrophic methanogenic archaea. Proc Natl Acad Sci U S A 108:2981-2986

Kaufmann F, Wohlfarth G, Diekert G (1997) Isolation of O-demethylase, an ether-cleaving enzyme system of the homoacetogenic strain MC. Arch Microbiol 168:136-142

Kiene RP, Oremland RS, Catena A, Miller LG, Capone DG (1986) Metabolism of reduced methylated sulfur compounds in anaerobic sediments and by a pure culture of an estuarine methanogen. Appl Environ Microbiol 52:1037-1045

Kröninger L, Berger S, Welte CU, Deppenmeier U (2016) Evidence for the involvement of two heterodisulfide reductases in the energyconserving system of Methanomassiliicoccus luminyensis. FEBS J 283:472-483

Kröninger L, Steiniger F, Berger S, Kraus S, Welte CU, Deppenmeier U (2019) Energy conservation in the gut microbe Methanomassiliicoccus luminyensis is based on membrane-bound ferredoxin oxidation coupled to heterodisulfide reduction. FEBS J 286:3831-3843

Kumar S, Stecher G, Tamura K (2016) MEGA7: molecular evolutionary genetics analysis version 7.0 for bigger datasets. Mol Biol Evol 33: 1870-1874

L'Haridon S, Chalopin M, Colombo D, Toffin L (2014) Methanococcoides vulcani sp. nov., a marine methylotrophic methanogen that uses betaine, choline and N,Ndimethylethanolamine for methanogenesis, isolated from a mud volcano, and emended description of the genus Methanococcoides. Int J Syst Evol Microbiol 64:1978-1983

Lang K, Schuldes J, Klingl A, Poehlein A, Daniel R, Brune A (2015) New mode of energy metabolism in the seventh order of methanogens as revealed by comparative genome analysis of "Candidatus Methanoplasma termitum.". Appl Environ Microbiol 81:1338-1352

Leahy SC, Kelly WJ, Altermann E, Ronimus RS, Yeoman CJ, Pacheco DM, Li D, Kong Z, McTavish S, Sang C, Lambie SC, Janssen PH, Dey D, Attwood GT (2013) The genome sequence of the rumen methanogen Methanobrevibacter ruminantium reveals new possibilities for controlling ruminant methane emissions. PLoS One 5: e8926

Lie TJ, Costa KC, Lupa B, Korpole S, Whitman WB, Leigh JA (2012) Essential anaplerotic role for the energy-converting hydrogenase Eha in hydrogenotrophic methanogenesis. Proc Natl Acad Sci U S A 109:15473-15478

Lomans BP, Maas R, Luderer R, Op den Camp HJM, Pol A, van der Drift C, Vogels GD (1999a) Isolation and characterization of Methanomethylovorans hollandica gen. nov., sp. nov., isolated from freshwater sediment, a methylotrophic methanogen able to grow on dimethyl sulfide and methanethiol. Appl Environ Microbiol 65: 3641-3650

Lomans BP, Op den Camp HJM, Pol A, van der Drift C, Vogels GD (1999b) Anaerobic versus aerobic degradation of dimethyl sulfide and methanethiol in anoxic freshwater sediments. Appl Environ Microbiol 65:438-443

Lomans BP, Op den Camp HJM, Pol A, van der Drift C, Vogels GD (1999c) Role of methanogens and other bacteria in degradation of dimethyl sulfide and methanethiol in anoxic freshwater sediments. Appl Environ Microbiol 65:2116-2121

Lomans BP, Leijdekkers P, Wesselink J-J, Bakkes P, Pol A, van der Drift C, Op den Camp HJM (2001) Obligate sulfide-dependent degradation of methoxylated aromatic compounds and formation of methanethiol and dimethyl sulfide by a freshwater sediment isolate, 
Parasporobacterium paucivorans gen. nov., sp. nov. Appl Environ Microbiol 67:4017-4023

Lomans BP, van der Drift C, Pol A, Op den Camp HJM (2002) Microbial cycling of volatile organic sulfur compounds. Cell Mol Life Sci 59: 575-588

Lyimo TJ, Pol A, Op den Camp HJM, Harhangi HR, Vogels GD (2000) Methanosarcina semesiae sp. nov., a dimethylsulfide-utilizing methanogen from mangrove sediment. Int J Syst Evol Microbiol 50:171-178

Lyimo TJ, Pol A, Harhangi HR, Jetten MSM, Op den Camp HJM (2009) Anaerobic oxidation of dimethylsulfide and methanethiol in mangrove sediments is dominated by sulfate-reducing bacteria. FEMS Microbiol Ecol 70:483-492

Major TA, Liu Y, Whitman WB (2010) Characterization of energyconserving hydrogenase B in Methanococcus maripaludis. J Bacteriol 192:4022-4030

Mayumi D, Mochimaru H, Tamaki H, Yamamoto K, Yoshioka H, Suzuki Y, Kamagata Y, Sakata S (2016) Methane production from coal by a single methanogen. Science 354:222-225

Miller MJ, Gennis RB (1985) The cytochrome $d$ complex is a coupling site in the aerobic respiratory chain of Escherichia coli. J Biol Chem 260:14003-14008

Mueller V, Blaut M, Gottschalk G (1986) Utilization of methanol plus hydrogen by Methanosarcina barkeri for methanogenesis and growth. Appl Environ Microbiol 52:269-274

Narihiro T, Kusada H, Yoneda Y (2016) Draft genome sequences of Methanoculleus horonobensis strain JCM 15517, Methanoculleus thermophilus strain DSM 2373, and Methanofollis ethanolicus JCM 15103, hydrogenotrophic methanogens belonging to the family Methanomicrobiaceae. Genome Announc 4(2):e00199-e00116

Oelgeschläger E, Rother M (2009a) In vivo role of three fused corrinoid/ methyl transfer proteins in Methanosarcina acetivorans. Mol Microbiol 72:1260-1272

Oelgeschläger E, Rother M (2009b) Influence of carbon monoxide on metabolite formation in Methanosarcina acetivorans. FEMS Microbiol Lett 292:254-260

Paul L, Krzycki JA (1996) Sequence and transcript analysis of a novel Methanosarcina barkeri methyltransferase II homolog and its associated corrinoid protein homologous to methionine synthase. J Bacteriol 178:6599-6607

Poehlein A, Schneider D, Soh M, Daniel R, Seedorf H (2018) Comparative genomic analysis of members of the genera Methanosphaera and Methanobrevibacter reveals distinct clades with specific potential metabolic functions. Archaea 2018:7609847

Rother M, Metcalf WW (2004) Anaerobic growth of Methanosarcina acetivorans $\mathrm{C} 2 \mathrm{~A}$ on carbon monoxide: an unusual way of life for a methanogenic archaeon. Proc Natl Acad Sci U S A 101:1692916934

Rother M, Oelgeschläger E, Metcalf WW (2007) Genetic and proteomic analyses of $\mathrm{CO}$ utilization by Methanosarcina acetivorans. Arch Microbiol 188:463-472

Schauer NL, Ferry JG (1982) Properties of formate dehydrogenase in Methanobacterium formicicum. J Bacteriol 150:1-7

Schauer NL, Ferry JG (1986) Composition of the coenzyme F420dependent formate dehydrogenase from Methanobacterium formicicum. J Bacteriol 165:405-411

Søndergaard D, Pedersen CNS, Greening C (2016) HydDB: a web tool for hydrogenase classification and analysis. Sci Rep 6:34212

Sorokin DY, Makarova KS, Abbas B, Ferrer M, Golyshin PN, Galinski EA, Ciordia S, Mena MC, Merkel AY, Wolf YI, van Loosdrecht MCM, Koonin EV (2017) Discovery of extremely halophilic, methyl-reducing euryarchaea provides insights into the evolutionary origin of methanogenesis. Nat Microbiol 2:17081

Sorokin DY, Merkel AY, Abbas B, Makarova KS, Rijpstra WIC, Koenen M, Sinninghe Damsté JS, Galinski EA, Koonin EV, van Loosdrecht MCM (2018) Methanonatronarchaeum thermophilum gen. nov. and 'Candidatus Methanohalarchaeum thermophilum', extremely halo(natrono)philic methyl-reducing methanogens from hypersaline lakes comprising a new euryarchaeal class Methanonatronarchaeia. Int J Syst Evol Microbiol 68:2199-2208

Sprenger WW, van Belzen MC, Rosenberg J, Hackstein JHP, Keltjens JT (2000) Methanomicrococcus blatticola gen. nov., sp. nov., a methanol- and methylamine-reducing methanogen from the hindgut of the cockroach Periplaneta americana. Int J Syst Evol Microbiol 50:1989-1999

Sprenger WW, Hackstein JHP, Keltjens JT (2005) The energy metabolism of Methanomicrococcus blatticola: physiological and biochemical aspects. Antonie Van Leeuwenhoek 87:289-299

Tallant TC, Krzycki JA (1996) Coenzyme M methylase activity of the 480-kilodalton corrinoid protein from Methanosarcina barkeri. J Bacteriol 178:1295-1301

Tallant TC, Krzycki JA (1997) Methylthiol:coenzyme M methyltransferase from Methanosarcina barkeri, an enzyme of methanogenesis from dimethylsulfide and methylmercaptopropionate. J Bacteriol 179:6902-6911

Tanaka K (1994) Anaerobic degradation of tetramethylammonium by a newly isolated marine methanogen. J Ferment Bioeng 78:386-388

Thauer RK (1998) Biochemistry of methanogenesis: a tribute to Marjory Stephenson. Microbiology 144:2377-2406

Thauer RK (2012) The Wolfe cycle comes full circle. Proc Natl Acad Sci U S A 109:15084-15085

Thauer RK, Kaster A-K, Seedorf H, Buckel W, Hedderich R (2008) Methanogenic archaea: ecologically relevant differences in energy conservation. Nat Rev Microbiol 6:579-591

Ticak T, Hariraju D, Bayron Arcelay M, Arivett BA, Fiester SE, Ferguson DJ (2015) Isolation and characterization of a tetramethylammonium-degrading Methanococcoides strain and a novel glycine betaine-utilizing Methanolobus strain. Arch Microbiol 197:197-209

van de Wijngaard WMH, Creemers J, Vogels GD, van der Drift C (1991) Methanogenic pathways in Methanosphaera stadtmanae. FEMS Microbiol Lett 80:207-211

van der Maarel MJEC, Hansen TA (1997) Dimethylsulfoniopropionate in anoxic intertidal sediments: a precursor of methanogenesis via dimethyl sulfide, methanethiol, and methiolpropionate. Mar Geol 137: $5-12$

Vepachedu VR, Ferry JG (2012) Role of the fused corrinoid/methyl transfer protein $\mathrm{CmtA}$ during $\mathrm{CO}$-dependent growth of Methanosarcina acetivorans. J Bacteriol 194:4161-4168

Wang H, Byrne JM, Liu P, Liu J, Dong X, Lu Y (2020) Redox cycling of $\mathrm{Fe}(\mathrm{II})$ and $\mathrm{Fe}(\mathrm{III})$ in magnetite accelerates aceticlastic methanogenesis by Methanosarcina mazei. Environ Microbiol Rep 12:97-109

Watkins AJ, Roussel EG, Webster G, Parkes RJ, Sass H (2012) Choline and N,N-dimethylethanolamine as direct substrates for methanogens. Appl Environ Microbiol 78:8298-8303

Watkins AJ, Rousse EG, Parkes RJ, Sass H (2014) Glycine betaine as a direct substrate for methanogens (Methanococcoides spp.). Appl Environ Microbiol 80:289-293

Welte C, Deppenmeier U (2011) Membrane-bound electron transport in Methanosaeta thermophila. J Bacteriol 193:2868-2870

Welte C, Deppenmeier U (2014) Bioenergetics and anaerobic respiratory chains of aceticlastic methanogens. Biochim Biophys Acta 1837: $1130-1147$

Welte C, Krätzer C, Deppenmeier U (2010) Involvement of Ech hydrogenase in energy conservation of Methanosarcina mazei. FEBS $\mathrm{J}$ 277:3396-3403

Welte C, Kröninger L, Deppenmeier U (2014) Experimental evidence of an acetate transporter protein and characterization of acetate activation in aceticlastic methanogenesis of Methanosarcina mazei. FEMS Microbiol Lett 359:147-153 
Widdel F (1986) Growth of methanogenic bacteria in pure culture with 2propanol and other alcohols as hydrogen donors. Appl Environ Microbiol 51:1056-1062

Widdel F, Rouviere PE, Wolfe RS (1988) Classification of secondary alcohol-utilizing methanogens including a new thermophilic isolate. Arch Microbiol 150:477-481

Worm P, Müller N, Plugge CM, Stams AJM, Schink B (2010) Syntrophy in methanogenic degradation. In: Hackstein $\mathrm{J}$ (ed) (Endo)symbiotic methanogenic archaea. Microbiology monographs, vol 19. Springer, Berlin, Heidelberg, pp 143-173

Zellner G, Winter J (1987) Secondary alcohols as hydrogen donors for $\mathrm{CO}_{2}$-reduction by methanogens. FEMS Microbiol Lett 44:323-328

Publisher's note Springer Nature remains neutral with regard to jurisdictional claims in published maps and institutional affiliations. 